IP Periodica Polytechnica

Transportation Engineering

43(2), pp. 67-72, 2015

DOI: 10.3311/PPtr.7580

Creative Commons Attribution (i)

RESEARCH ARTICLE

\section{Mobility Issues in Selected Regions of Poland and Slovakia - Outcomes of International Project SOL (Save Our Lives) Survey}

\author{
Dagmara Jankowska ${ }^{1}$, Miroslava Mikušová2, \\ Justyna Wacowska-Ślezak ${ }^{1}$ \\ Received 02 May 2014; accepted 07 May 2014
}

\begin{abstract}
The paper briefly describes the methodology and procedure for carrying out the public opinion survey which was focused on selected mobility issues. The survey was realized in 10 regions of Central Europe. Paper also sums up the outcomes of the evaluation of the travel preferences and public attitudes towards problems and risk factors of road safety and potential effectiveness of authorities in the Warmia-Mazury region in Poland and Zilina region in Slovakia. The survey was implemented with the support of a single methodology developed by partner organizations of international project SOL - Save Our Lives.
\end{abstract}

\section{Keywords}

mobility, road transport safety, survey

\footnotetext{
${ }^{1}$ Motor Transport Institute, Jagiellonska 80, 03-301 Warsaw, Poland

${ }^{2}$ University of Zilina, Univerzitna 8215/1, 01026 Zilina, Slovakia

*Corresponding author, e-mail: dagmara.jankowska@its.waw.pl
}

\section{Introduction}

The main objectives of the public opinion and knowledge survey for the international project SOL were to understand respondents' attitudes regarding:

- travel preferences and the link between road safety and sustainable mobility,

- general road safety attitudes, such as the perception of risks of a road crash by a pedestrian, cyclist, in comparison to other risks, based on the international experiences (Beheshtitabar et. al, 2014)

- perception of child injury risks in traffic,

- biggest risk factors in a region and whether a government is tackling road safety issues well enough.

The survey outcomes could be used:

- to support the strategy of development,

- for advocacy purposes (the importance of the survey as an advocacy tool to show the local government the concerns, opinions and views of the public in relation to road safety and mobility issues). That is strongly in line with international experience (Beke et. al, 2014).

\section{Methodology and implementation of the survey}

The survey was conducted during the SOL (Save Our Lives) project with a use of quantitative method and by means of an online questionnaire. The questionnaire was prepared in cooperation with Motor Transport Institute in Warsaw and with all SOL project partners. The external subcontractor and coordinator of the survey was Agencja Psyche (Psyche Agency). The external consultancy allowed immediate preparation of the Internet survey platform and faster data collection (Maj and Bedyńska, 2011). After the development of the questionnaire, it was translated into all languages of the partner countries (Kiss et. al., 2013), and then placed on a special platform used for on-line surveys powered by mysurveylab.com.

A link to survey was distributed by different channels, among others, by means of:

- emails sent to local entities (universities, local authorities, companies, private persons),

- emails sent to local mass media representatives (request for placing a link on their pages), 
- social media, e.g. Facebook,

- message sent to all relevant users of the Euro26 card,

- direct, local activity of SOL partners.

\section{Basic data about the sample of the respondents}

The survey covered $7 \mathrm{EU}$ countries with results coming from 2956 people who filled in the questionnaire. Below, a list of locations together with information on a number of participants in individual countries is provided. According to the directives in case of two countries - Slovakia and Slovenia - data were divided into regions covered by the survey. There were also 235 people who did not declare the location or were from the territory different than the listed ones. These data were not analyzed. The total number of analyzed responses was 2721 .

Table 1 Locations considered in the survey and number of participants.

\begin{tabular}{|c|c|c|}
\hline Country & Region & $\mathbf{N}$ \\
\hline Austria & Steiermark & 211 \\
\hline Czech Republic & Liberec Region & 205 \\
\hline Hungary & Gyor & 486 \\
\hline Italy & $\begin{array}{c}\text { Eastern Lombardia (Mantua, Brescia, } \\
\text { Cremona, Bergamo) }\end{array}$ & 459 \\
\hline Poland & Warmia-Mazury Region & 253 \\
\hline Slovenia & Tolmin & 116 \\
\hline Slovenia & Kocevje & 183 \\
\hline Slovenia & Maribor & 231 \\
\hline Slovakia & Zilina Region & 453 \\
\hline Slovakia & Presovsky Region and city of Presov & 124 \\
\hline TOTAL & & 2721 \\
\hline
\end{tabular}

Number of respondents who filled in the online questionnaire was $453(16 \%)$ for the Žilina region in Slovakia and 253 $(9,3 \%)$ for Warmia-Mazury region in Poland, out of total 2721 respondents. The average age of the respondents in Žilina was 30,5 years with the following educational structure: primary education - $15,9 \%$, secondary grammar school education $8,8 \%$, secondary school education $-18,1 \%$, vocational secondary education $-4,6 \%$, higher education $-52,2 \%$. For WarmiaMazury the average age of respondents was 35,55 years with educational structure: primary education $-0,4 \%$, secondary grammar school education - 1,2\%, secondary school education $-27,3 \%$, vocational secondary education $-3,2 \%$ and university/college education - 66,8\%. In Žilina sample, $66,3 \%$ of the respondents had driving license with the average 10,1 years of driving experience and the average annual car kilometres driven - $23365 \mathrm{~km}$. In Warmia-Mazury - 89,33\% of respondents had driving license with the average 11,07 years of driving experience and annual average of 24094 car $\mathrm{km}$ driven. The samples in this aspect are quite similar, despite the differences of educational structure of respondents from these countries.

\section{Outcomes of the survey}

In the following paragraphs, a short overview of the results for each category will be provided for both countries.

\subsection{Travel preferences and mobility characteristics in the region}

\subsubsection{Travel mode to work and school}

Results from the Žilina region survey showed that the typical way to school/work is done by car $(45 \%)$ or bus $(41 \%)$. Significantly fewer respondents go to work or school by train (14\%) or bicycle (5\%). $26 \%$ of the respondents travel to school on foot and $0,7 \%$ of all respondents don't travel to work or school.

In Warmia-Mazury region three quarters of the respondents (75\%) get to work or school by car, $23 \%$ go by bus, and $22 \%$ go on foot. Only a few ride a bicycle (9\%), or get to work/ school by train $(4 \%)$.

We can observe quite big differences between both countries. In Slovakia it could be caused by the fact that the fare price by commuter bus operators is constantly increasing, while supply of connections in rail transport is decreasing.

It should be remembered, that in case of this question it was possible to mark few answers. That is the reason the percentage rate does not add to $100 \%$.

\subsubsection{Distance to the civil facilities}

The survey participants were also asked to estimate the distance (in kilometres) from their home to many different places with civil facilities. In Žilina region the respondents indicated that the longest average distance is to school or work $(19,4$ $\mathrm{km})$. The distance to significant public offices is much shorter $(7,66 \mathrm{~km})$, as well as the one to the nearest post office $(5,2 \mathrm{~km})$. The shortest distance Žilina inhabitants have to reach public transport stations $(4,1 \mathrm{~km})$ and local shops $(3,3 \mathrm{~km})$. The total estimated average distance traveled by the respondents during the calendar day was $30,1 \mathrm{~km}$.

In Warmia-Mazury region on average the respondents indicated the longest distance to school or work $(17,6 \mathrm{~km})$, the distance to significant public offices was a little bit shorter $(12,1$ $\mathrm{km})$, as well as to the nearest post office $(7 \mathrm{~km})$, and local shops $(5,6 \mathrm{~km})$. The shortest indicated distance concerns public transport stations $-3,2 \mathrm{~km}$. On average the respondents declared that their usual travel distance per day is $41,70 \mathrm{~km}$.

When estimating the distance, respondents should take into account all their movements within the ordinary calendar day.

\subsubsection{The assessment of public transport quality}

The survey respondents evaluated the level of selected quality characteristics of the public transport with the values from 
1 to 7 . The value around " 1 " meant poor and around "7" very good quality of services provided by carriers.

In Žilina region the highest score relates to accessibility $(4,70)$, punctuality $(4,36)$ and safety $(4,38)$. The comfort had a lower score $(3,63)$, as well as draft timetable $(3,68)$. With a use of a 7-point scale, the quality of public passenger transport is valued as average and in case of comfort and draft timetable as below-average.

In Warmia-Mazury region the highest score relates to accessibility $(4,15)$, punctuality $(4,02)$, and safety $(3,88)$. The comfort had a lower score $(3,02)$, as well as comfortable working hours $(3,47)$.

\subsection{General Road Safety Attitudes \\ 4.2.1 Road infrastructure safety}

The respondents from Zilina region in Slovakia evaluated road safety in their region providing an approximate score of 3,62 (as an answer to question: "How safe are your region's roads to travel on?"). The respondents evaluated the situation when roads were considered to be dangerous with score " 1 " and roads which were considered to be safe with score "7".

Based on the calculated average values of the survey, the roads in Žilina region are considered as more or less dangerous. In Warmia-Mazury, the respondents evaluated safety of roads providing an approximate score of 2,76, so they felt the roads in their region are less safe than in Slovakia region.

\subsubsection{Impact assessment of the selected measures on road safety}

The question: "Do you think that the solutions given below contribute to increasing road safety?" made possible the quantification of selected measures impact to increase road safety. In this question the respondents evaluated their attitudes towards different statements concerning road safety, with a use of 7-point scale (1 - I do not agree at all, 7 - I agree completely).

In Žilina region the most efficient ways to improve road safety were listed as follows: using child restraints $(5,76)$, using safety belts $(5,35)$, and making drink-driving laws more strict $(5,40)$. Less people indicated existing speed limits $(4,82)$ and speed cameras $(4,53)$.

In Warmia-Mazury region scoring was as follows: using child restraints $(6,00)$, using safety belts $(5,48)$, and making drink-driving laws more strict $(5,40)$. Also less people indicated existing speed limits $(4,52)$ and speed cameras $(3,48)$.

\subsubsection{Changes in the used model of road safety}

Respondents' incentives on making changes under the current model of road safety were identified by question "What should be changed in order to increase road safety (police checks/fines/publicity and advertising)?". This question was focused on changes in the system of police checks, the system of fines, publicity and advertising.
Responses in both regions are expressed in the graphs (see Fig. 1 and Fig. 2) in order to improve comparison and make it more transparent. The respondents indicated if an individual factor of influence should be increased, decreased or should remain at the same level.

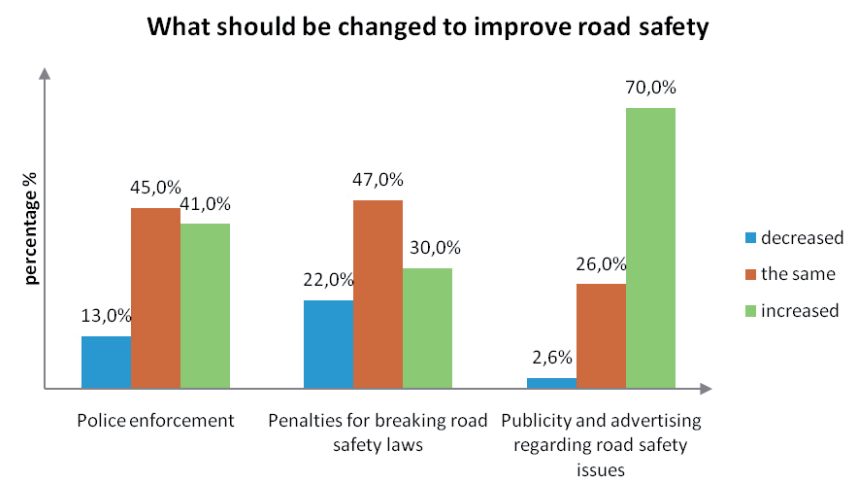

Fig. 1 Respondents' attitudes to change of the selected road safety measures in Žilina region.

In Žilina region the data show that in case of police enforcements the respondents are divided - almost equally. Almost half of them think that the measures should remain at the same level $(45 \%)$ and $41 \%$ that they should be intensified. When it comes to penalties for breaking road safety laws - they should rather remain at the same level $(47 \%)$, although some people would like them to be higher $(30 \%)$. In case of publicity and advertising regarding road safety issues, most of the respondents think that it should be increased (70\%), however, there is a group of people claiming that the current actions in that matter are sufficient (26\%).

In Warmia-Mazury region data show that in case of police enforcement the respondents think that they should be intensified $(54,2 \%)$, or remain at the same level $(36,8 \%)$. When it comes to penalties for breaking road safety laws - they should be increased $(43,1 \%)$, or remain at the same level $(44,3 \%)$, less people claim that they should be decreased $(10,7 \%)$. In case of publicity and advertising regarding road safety issues, most of the respondents think that it should be increased $(76,3 \%)$, however, a group of people claim that the current actions in that matter are sufficient $(19,4 \%)$.

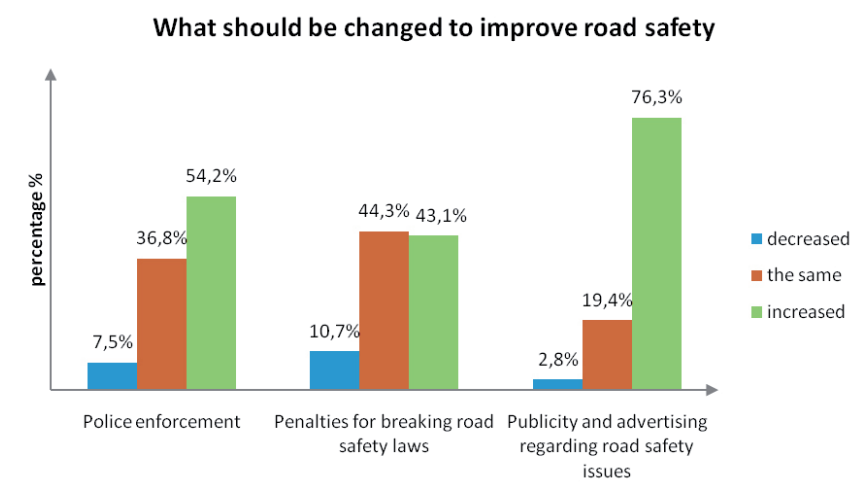

Fig. 2 Respondents' attitudes to change of the selected road safety measures in Warmia-Mazury region. 


\subsubsection{Perception of the selected factors' impact on road safety}

In statement: "Road safety mainly depends on...", the respondents evaluated factors which influence road safety according to a 7-point scale.

In opinion of respondents from Žilina region road safety mainly depends on the behaviour and culture of road users $(5,98)$. Then they indicated design and standard of roads, education and trainings, effective law enforcement or traffic regulations, which were less significant for them (on average - above 5).

For Warmia-Mazury region the respondents stated that road safety mainly depends on the behaviour and culture of road users $(6,58)$, design and standard of roads $(5,98)$ and education and trainings $(5,83)$. A little less significant was effective law enforcement $(5,70)$, as well as traffic regulations $(5,22)$.

\subsection{Risk Factors}

\subsubsection{Public perception of road situations}

The respondents answered the following question according to a 7-point scale: "To what extent do you agree with the following statements?" (1 - total disagreement, 7 - total agreement). Based on the average value of respondents' assessments, specific statements of direct agreement or disagreement with these statements are not confirmed. Respondents agree with the statement that they are responsible for "what happens on the road" $(4,79)$, tend to agree with statements that "dangerous situations on the road happen to us because of our fault" $(4,21)$, as well as "I often feel that I do not have influence on things that happen to me on the road" $(4,09)$. The statement "Some people do not have luck in life and as well they don't have it on the road" other respondents more or less don't agree $(3,09)$. It is quite clear that respondents from Žilina region are aware of their impact on road safety.

For Warmia-Mazury region the mean results are presented in following table (Table 2).

Table 2 Outcomes of Warmia-Mazury region respondents' to question: “To what extent do you agree with the following statements?".

\begin{tabular}{lc}
\hline \multicolumn{1}{c}{ Statement } & M \\
\hline $\begin{array}{l}\text { Dangerous situations on the road happen to us because of a } \\
\text { bad luck. }\end{array}$ & 4,30 \\
\hline $\begin{array}{l}\text { I often feel that I do not have influence on things that happen } \\
\text { to me on the road. }\end{array}$ & 5,55 \\
\hline $\begin{array}{l}\text { I am responsible myself for things that happen to me on the } \\
\text { road. }\end{array}$ & 2,80 \\
\hline
\end{tabular}

\subsubsection{Breaking of the traffic laws}

By answering the question "How often in recent months...?" respondents evaluated the frequency of breaking the basic road safety principles. Seven-point rating scale was used for the evaluation ( 1 - never, 2 - very rarely, 3 - rarely, 4 - occasionally, 5 - often, 6 - very often, 7 - always).
Among the negative behaviour included in the questionnaire, the respondents from Žilina region mainly indicated exceeding the speed limit $(3,87)$, transporting passengers who hadn't had their safety belts fastened $(3,50)$, transporting children without child restraint system $(3,29)$, or going by car without safety belts fastened $(2,86)$. It also happened that the drivers were driving under the influence of alcohol $(2,54)$.

For Warmia-Mazury region the rating was as follows: exceeding the speed limit $(4,06)$, transporting children without child restraint system $(3,81)$, and transporting passengers who hadn't had their safety belts fastened $(2,99)$. It also happened that the respondents were going by car without safety belts fastened $(2,34)$ or they were driving under the influence of alcohol (2,03).

\subsection{Efficiency of authorities in the scope of road safety in the region \\ 4.4.1 Infrastructure for pedestrians and cyclists}

Assessment of the infrastructure existence for pedestrians or cyclists was the content of the question: "Do you think there is a sufficient number of the following in your area?", where respondents evaluated the infrastructure according to 7-point scale (1 missing infrastructure, 7 - good quality of infrastructure).

Žilina region respondents perceive the infrastructure for pedestrians and cyclists, with the exception of pedestrian crossings $(4,0)$, as not sufficient and in case of infrastructure for cyclists as almost not satisfactory.

According to the respondents of Warmia-Mazury region the following are satisfactory in the provided scope: a number of zebra crossings $(4,36)$, sidewalks $(3,94)$, pedestrian crossings with lights $(3,30)$, and bike lanes $(2,28)$. The number of bicycle racks/parking $(1,73)$ was not as satisfactory as the above.

\subsubsection{Traffic control}

The average number of traffic controls that respondents from Žilina region were subject to was almost two $(1,91)$, while from Warmia-Mazury province $-1,42$. The chance of being stopped for traffic offences was 4,24 in Žilina region, and 3,02 in Warmia-Mazury region, evaluated according to a 7-point scale (1 - very little chance, 7 - very strong chance of penalty for performed offence).

In practice it means that if the participant is involved in traffic offense, he/she will be fined with the probability slightly higher than $50 \%$.

\subsubsection{The will of public to change habits}

The questions "Would you walk/cycle more often if..." aimed at identification of factors which contribute to walking/ cycling.

The factor that would influence it most in Žilina region concerns more careful drivers $(4,56)$ and better lightening of streets $(4,14)$. The other factors were: improvement of sidewalks 
$(3,97)$, safety monitoring $(3,83)$ and smaller distance between pedestrian crossings $(3,60)$.

The factor that would influence cycling more concerns development of more bicycle lines $(5,19)$. The following issues were less significant: more lighting on streets $(4,56)$ and more bicycle racks/parking $(4,33)$.

In Warmia-Mazury region the numbers are a little bit lower - the factor that would influence walking most is that the drivers are more careful $(4,29)$. Other less significant issues with a similar meaning are: safety monitoring $(3,75)$, better lightening of streets $(3,59)$, improvement of sidewalks $(3,54)$, and smaller distance between pedestrian crossings $(3,31)$.

The factor that would influence cycling most concerns development of more bicycle lines $(5,77)$. The following issues were less significant: more bicycle racks/parking $(5,17)$ or more lighting on streets $(4,93)$.

\section{Summary of results}

The analysis confirmed that most of the respondents who participated in the survey get to work by car (especially in the analyzed region of Poland) that is inline with the international experience (Capros, 2012). However, there are regions where going by bus is also popular (including Žilina region in Slovakia). From all the regions participating in the survey walking is most common in the selected areas of Poland and Slovakia.

On average, in everyday travel, the respondents have the biggest distance to work/school. This could be linked with the preference of car usage - the longest distance to work place, e.g. in case of Poland, requires fast and convenient transportation mode which would be a car in that case confirmed in the highest usage of that mode of transport. The distances to other locations are quite diverse - usually the local shops can be reached within a short distance, and public offices within a little longer travel.

The scores provided for the evaluation of the local public transport are above the average. The worst opinions were given by inhabitants of the selected region of Poland.

Usually, accessibility of public transport was evaluated with the highest score. Respondents also assessed safety in public transport with high rates. The lowest ranks were given for comfortable working hours. In case of analyzed regions of Poland and Slovakia, comfort in public transport was evaluated with the lowest score.

The worst opinions concerning safety of local roads were provided by the inhabitants of the selected region in Poland.

According to the respondents, road safety mainly depends on the usage of child restraint system, and the least on speed cameras and existing speed limits. Strict drink-driving laws seem important for the inhabitants of Slovakia.

The majority of respondents also claimed that it is necessary to intensify publicity and advertising regarding road safety issues. When it comes to police enforcements, the opinions are divided (however, there is a small number of people who want to decrease them).

The respondents from the Polish region significantly want to increase police enforcements. The respondents from Slovakia want them to be maintained at the same level. That applies also to penalties for breaking road safety laws.

In both Polish and Slovakian locations subject to the survey, the respondents claimed that the factor that influences road safety the most is behavior and culture of road users (Jankowska, Wacowska-Slezak, 2010). The role of education and trainings was also emphasized. However, it should be mentioned that other factors were also perceived as important ones.

The questions concerning the perception of road situation proved that respondents have a low sense of control on what is happening on the road - the lowest scores were provided by the respondents from Poland, and relatively high by the respondents from Slovakia.

The question concerning negative behavior of the respondents on the road, which have occurred in the recent months, showed that survey participants mostly exceed speed limits. In analyzed region of Poland children are sometimes transported without child restraint systems. There are also other cases, rarer, where some respondents forget to fasten their safety belts.

In case of infrastructure for pedestrians, the opinion on zebra crossings and sidewalks is quite good, but there is a significantly bad opinion concerning infrastructure for cyclists (Torok, 2013) (bike lanes, bicycles racks/parking). It seems that those factors were especially important for respondents from Poland and Slovakia.

The obtained data show that the respondents of the selected region of Slovakia were stopped for the traffic control most often. Generally, the possibility of being stopped for such a control was evaluated by the respondents as average one.

The conducted survey also showed that the factor that would encourage the respondents to walk more concerns more careful drivers. In case of Poland safety monitoring was also very important (Jankowska, Wacowska-Slezak, 2011).

\section{Conclusions}

Data collection for this survey was very limited in time, (10 days long on-line survey) therefore it was possible to collect only limited number of answers from respondents representative for each region. Despite that, the survey results for both countries - Poland and Slovakia - can be considered statistically significant, but taking into account the reserve of the questionnaire outcomes, which are not considered as accurate by the scientific community, but only approximate. The law of large numbers indicates that if we increase the sample size, research outcomes would be more and more similar to the reality. So it would be interesting to continue the study or/ and to repeat the questionnaire in a modified version after the implementation of the SOL project in the pilot locations. The 
second wave of a quantitative study would allow to check the effectiveness of the implemented programs.

In general terms, it is possible to conclude that conducted survey gave a comprehensive picture of mobile preferences and daily behavior in traffic in the selected regions. The study gave also a picture of risks and road safety perception among respondents. These findings need to be taken into account in the road safety and mobility draft strategy and action plans to address crucial problems of road safety in the regions (Mikušová, Cyprich, 2011).

In each part of the questionnaire evaluation, mobility and road safety problems were identified as well as related disciplines. In the future, the main aim should be to find concrete solutions for these problems, which would be acceptable by the general public. Outcomes of public opinion survey will certainly help in solving the serious road safety problems, when the appropriate alternative solutions will be selected.

\section{Acknowledgement}

The project presented in this article is supported by KTI Institute for Transport Sciences, and project SOL - Save Our Lives.

\section{References}

Beheshtibar, E., Ríos, S. A., König-Hollerwöger, D., Svatý, Z., Rydergren, C. (2014) Route Choice Modelling For Bicycle Trips. International Journal for Transport and Traffic Engineering. 4 (2). pp. 194-209. DOI: 10.7708/ijtte.2014.4(2).06

Beke, B. M., Sipos, T., Torok, A. (2014) The Mathematical Modelling of the Road Safety Equipment's Market Penetration. American Journal of Vehicle Design. 2 (1). pp. 1-6. DOI: 10.12691/ajvd-2-1-1
Capros, P. et al. (2012) Europead energy and transport: Trends to 2030. [online]. Available from: http://ec.europa.eu/dgs/energy_transport/ figures/_trends_2030_update2007/energy_transport_trends_2030_ update 2007_en.pdf. [Accessed: 16 ${ }^{\text {th }}$ January 2012]

Jankowska, D., Wacowska-Ślezak, J. (2010) Kompleksowa strategia bezpieczeństwa ruchu drogowego dla Europy Środkowej. (A comprehensive road safety strategy for Central Europe - Projekt SOL (Save Our Lives). Quaterly Magazine BRD, ITS, no.4/2010. (in Polish)

Jankowska, D., Wacowska-Ślezak, J. (2011) Ocena sytuacji bezpieczeństwa ruchu drogowego $w$ regionach - badania opinii społecznej. (Assessment of the road safety situation in the Central-East European regions.) Quaterly Magazine BRD, ITS, no.2/2011. (in Polish)

Kiss, A. O., Sesztakov, V., Török, Á. (2013) Road Safety Analysis in Győr. Periodica Polytechnica Transportation Engineering. 41 (1). pp. 51-56. DOI: 10.3311/PPtr.7098

Maj, K., Bedyńska, S. (2011) Public opinion and knowledge survey about road safety: Results of the 2011 survey [outcomes of specialized study]. Warsaw, Psyche agency. 2011. (non-public document)

Mikušová, M., Cyprich, O. (2011) Význam realizácie situačného vyhodnotenia v rámci tvorby stratégií pre zvyšovanie bezpečnosti cestnej premávky. (The importance of implementing situ-ational assessment in road safety strategies.) In: Bezpečnost' cestnej premávky: zborník recenzovaných prispevkov z konferencie. (Transport 2011 - Road safety: Reviewed Conference Proceedings.) - Žilina: Žilinská univerzita], pp. 75-79, ISBN 978-80-554-0439-4. (in Slovakian)

Torok, A. (2013) Simplification of Road Transport Infrastructure Layout for Better Self-Explanation. American Journal of Vehicle Design. 1 (1). pp. 16-20. DOI: 10.12691/ajvd-1-1-3

Vujanić M., Pešić, D., Antić, B., Smailović, E. (2014) Pedestrian Risk At The Signalized Pedestrian Crossing Equipped With Countdown Display. International Journal for Transportation and Traffic Engineering. 4 (1). pp. 52-61. DOI: $10.7708 /$ ijtte.2014.4(1).04 